\title{
EDITORIAL \\ The Rhoton Collection and the Journal of Neurosurgery: expanding the reach of neuroanatomy in the digital print world
}

\author{
James T. Rutka, MD, PhD, FRCSC \\ Editor-in-Chief, Journal of Neurosurgery Publishing Group, Charlottesville, Virginia
}

I HAVE always maintained that of all the neurosciences we must master to care best for our patients, the most important one for us, as neurosurgeons, is neuroanatomy. Neuroanatomy is the cornerstone on which we build our understanding of the structure and function of the human brain, spinal cord, and peripheral nerves. I vividly recall spending countless hours of my neurosurgical residency reading neuroanatomical textbooks, skull in hand, learning the nuances of approaches to the brain. I yearned for neuroanatomy texts that had practical neurosurgical anatomy at their core.

Advances in neurosurgery have unquestionably been aided by leaders in neurosurgery who have devoted their careers to improving our abilities to reach regions of the brain with as much accuracy and as little morbidity as possible. Of the contemporary "neurosurgical anatomists" who have guided our field toward improved outcomes, perhaps none has been as influential or has had as much impact as Dr. Albert L. Rhoton Jr. Over the years, Dr. Rhoton has published numerous neuroanatomical studies in the Journal of Neurosurgery that have served as the ultimate resource on topics such as the microsurgical anatomy of the central lobe, ${ }^{1}$ the microsurgical anatomy of the choroidal arteries, ${ }^{2}$ the limitations of the transcallosal transchoroidal approach to the third ventricle, ${ }^{4}$ and the telovelar approach to the fourth ventricle, ${ }^{3}$ among many others.

Many of the neuroanatomical figures from Dr. Rhoton's elegant studies have been captured in the "Rhoton Collection," which is freely available to members of the American Association of Neurological Surgeons (AANS). On this website, you can search the collection for innumerable 2D- and 3D-format neuroanatomical dissections, watch Dr. Rhoton's lectures, and browse the atlas that has been created online. The Rhoton Collection was made possible through the indefatigable efforts of Dr. Jeffrey Sorenson of Semmes-Murphey Neurosurgical Clinic in Memphis, Tennessee, and through the financial support of the Neurosurgery Research and Education Foundation (NREF) and the AANS.

In this issue of the Journal, I am proud to announce the expanded capabilities of selected neuroanatomical studies when viewed through our website (www.thejns.org). The enhancements are shown in the article by Frigeri et al. ${ }^{1}$ The reader will go to "Article Tools" on the left-hand side of the article and then click on "Show Anatomy Links" (Fig. 1). This will immediately highlight neuroanatomical

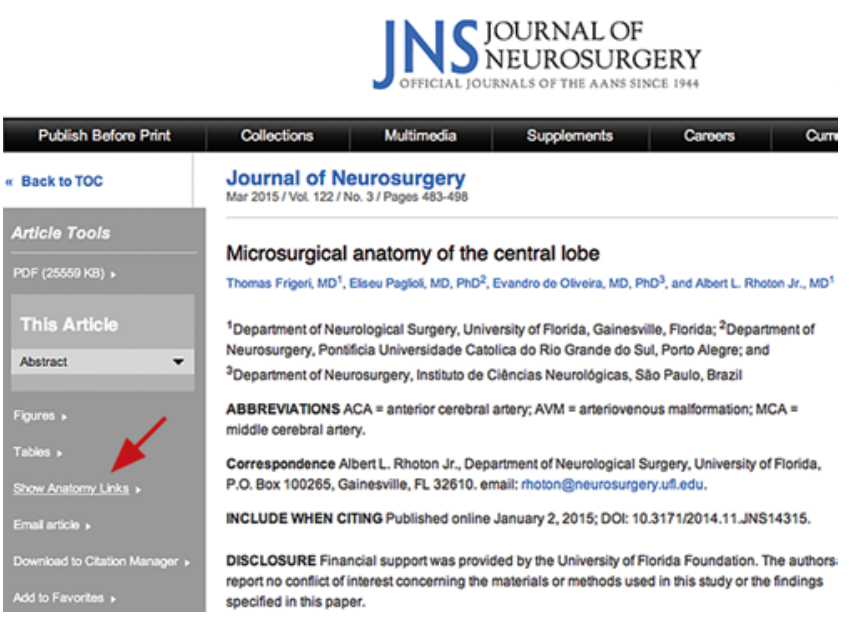

FIG. 1. Screenshot of the Rhoton-enabled Frigeri et al. article as it appears on the Journal of Neurosurgery website (www.thejns.org). The reader can click on "Show Anatomy Links" (red arrow) in the Article Tools to enable the anatomy viewer. Figure is available in color online only. 


\section{Methods}

The central lobe was examined under magnifications of $\times 3$ to $\times 40$ in 20 formalin-fixed cadaveric hemispheres in which the arteries were perfused with red and the veins with blue silicone. The frontal and parietal bones were removed while preserving the coronal suture to study its relationship with the anterior and posterior limits of the Precentral Gyrus. The arachnoid membrane was removed from the gyral surfaces and variations in the sulci and gyri were examined. The inclination of the Central Sulcus and coronal suture compared with their coronal planes was measured. The distances between the coronal suture and the anterior and posterior limits of the precentral gyrus were established at $1 \mathrm{~cm}$ intervals from their upper to their lower ends. The arterial branches supplying the central lobe were followed from their origin to their termination. The Sylvian Fissure was opened widely to determine the arterial trunks, stem arteries, and cortical branches supplying the central lobe. The veins and drainage pathways of the central lobe were defined.

FIG. 2. Screenshot of the Methods section of the Frigeri et al. article. When the Rhoton viewer is enabled, active anatomy terms appear as blue text with underlining. Figure is available in color online only.

terms in the text of the article (Fig. 2). When the reader clicks on these words in the article, a Rhoton Collection high-resolution figure of the highlighted neuroanatomical structure is displayed (Fig. 3).

Please be assured that authors of associated articles in the Journal have agreed to participate in this initiative. As
I see it, this is a powerful way to take full advantage of the legacy materials within the Rhoton Collection and to underscore the importance of the authors' neuroanatomical studies. Such linkages would not be possible without our ability to automate the identification of neuroanatomical terms within Journal articles and to provide coherent

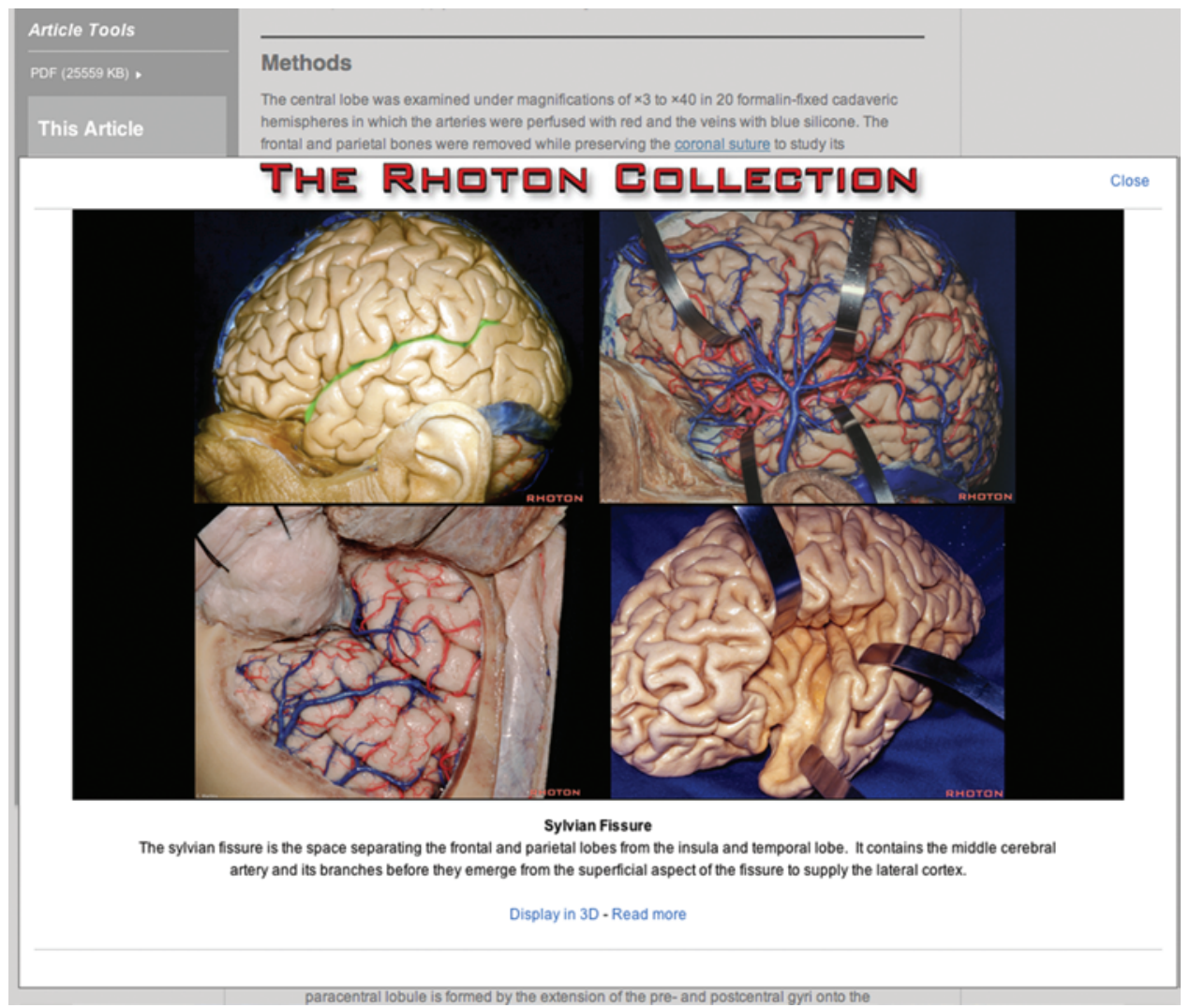

FIG. 3. Screenshot of the Frigeri et al. article after a Rhoton search term has been selected; the Rhoton image appears within the Journal article so that the reader can access the anatomy image immediately and then return to reading the article. Figure is available in color online only. 
computer code terminology. For this I thank Mr. James Dell, IT Systems and Services Manager of the JNS Publishing Group, in addition to Dr. Sorenson.

For students of neuroanatomy, few things could be better than reading through primary source material within the Journal and linking to the works of the Rhoton Collection. As a neurosurgeon who has been an end user of neuroanatomy textbooks for decades, this association between the Journal and the Rhoton Collection has motivated me to study neuroanatomy all over again! I do hope you are similarly inspired.

http://thejns.org/doi/abs/10.3171/2015.12.JNS152878

\section{References}

1. Frigeri T, Paglioli E, de Oliveira E, Rhoton AL Jr:
Microsurgical anatomy of the central lobe. J Neurosurg 122:483-498, 2015

2. Fujii K, Lenkey C, Rhoton AL Jr: Microsurgical anatomy of the choroidal arteries: lateral and third ventricles. J Neurosurg 52:165-188, 1980

3. Mussi AC, Rhoton AL Jr: Telovelar approach to the fourth ventricle: microsurgical anatomy. J Neurosurg 92:812-823, 2000

4. Ulm AJ, Russo A, Albanese E, Tanriover N, Martins C, Mericle RM, et al: Limitations of the transcallosal transchoroidal approach to the third ventricle. J Neurosurg 111:600-609, 2009

\section{Disclosures}

The author reports no conflict of interest. 